\title{
Maximum warning times for imminent volcanic eruptions
}

\author{
Christopher R. J. Kilburn and Peter R. Sammonds ${ }^{1}$ \\ Benfield Hazard Research Centre, Department of Earth Sciences, University College London, London, UK
}

Received 25 July 2005; revised 24 October 2005; accepted 1 November 2005; published 29 December 2005.

[1] Accelerations in seismicity are important precursors to eruptions at volcanoes reawakening after extended repose intervals. These have previously been quantified for subduction-zone settings in terms of the linkage of crustal faults by shearing. Introducing a damage-mechanics criterion for the weakening of rock between major fractures, the model is here modified for failure in tension, consistent with conditions in crust surrounding a pressurized magma reservoir. The results indicate that final accelerations develop over $\sim 2-3$ weeks at tensile strains of $(4.5 \pm 3.2) \times 10^{-3}$. Since a week or more is required to identify an accelerating trend, seismic forecasts of eruptions after long repose are unlikely to be reliable more than days in advance. Improvements will require the integration of additional precursors or extension of the model to earlier stages of fracture growth in stressed crust. Citation: Kilburn, C. R. J., and P. R. Sammonds (2005), Maximum warning times for imminent volcanic eruptions, Geophys. Res. Lett., 32, L24313, doi:10.1029/2005GL024184.

\section{Introduction}

[2] Volcanic eruptions are commonly preceded by shortterm increases in geophysical and geochemical parameters, from rates of seismicity and of ground deformation to rates of gas release [Scarpa and Tilling, 1996]. Quantifying such increases is important for defining the maximum warning times that can be expected during a volcanic crisis. Increases in seismic event rate are particularly important, since these are often the first, and sometimes the only, quantitative data available during emergencies at previously unmonitored volcanoes.

[3] We here focus on seismic precursors to eruptions at andesitic-dacitic volcanoes that have been in repose for a century or more. Such volcanoes are associated with subduction zones and have been chosen because they have produced the largest explosive eruptions during the past 200 years [Simkin and Siebert, 1994] and are the types for which repeatable precursory patterns are most evident [Kilburn, 2003]. Repeatable patterns have yet to be identified at volcanoes not in subduction zones [Linde et al., 1993; Chastin and Main, 2003; Collombet et al., 2003] and, on occasion, they may also be absent or obscured before eruptions at subduction-zone volcanoes [Endo et al., 1981]. This paper, therefore, considers only one part of the spectrum of seismic precursors to eruptions.

\footnotetext{
${ }^{1}$ Also at Mineral, Ice, and Rock Physics Laboratory, Department of Earth Sciences, University College London, London, UK.
}

\section{Accelerations in Pre-Eruptive Seismicity}

[4] The idea that accelerations in precursory seismicity might follow constrained and repeatable patterns has been encapsulated by the Voight Relation [Voight, 1988, 1989], according to which the acceleration in seismic event rate, $d^{2} N / d t^{2}$, increases with the rate, $d N / d t$, as

$$
d^{2} N / d t^{2}=K(d N / d t)^{\alpha}
$$

where $N$ is the number of seismic events detected in time $t$, $K$ is a constant and $\alpha$ lies between 1 and 2 . When $\alpha=1$, the event rate increases exponentially with time; when $\alpha=2$, it increases hyperbolically with time [Kilburn and Voight, 1998; Kilburn, 2003].

[5] The limiting regimes can be explained by the interaction of a large number of fractures and faults that grow under a slow-cracking regime (Figure 1) [McGuire and Kilburn, 1997; Kilburn and Voight, 1998; Kilburn, 2003]. Most precursory seismicity tends to be concentrated within a volume $V_{s}$ of crust $\sim 10 \mathrm{~km}^{3}$ below a volcano and, with Richter Magnitudes typically between 0 and 2, involves fault lengths $L_{f} \sim 10-100 \mathrm{~m}$ [Kilburn, 2003]. For an even distribution of discontinuities, the number of faults that potentially could yield detectable seismicity is $\sim V_{s} / L_{f}^{3} \sim$ $10^{5}-10^{6}$. When first applied, the magmatic stress concentrates around the tips of discontinuities until it is large enough to bring faults to the condition of activation (or of first movement). Activation is not simultaneous, but spreads as the first fractures to extend disturb the overall stress field by static stress transfer and by the propagation of seismic waves [Hill et al., 2002].

[6] Initially, the event rate increases with the number of activated fractures and, hence, with the number of events that have occurred, yielding an exponential increase with time (equation (1) with $\alpha=1$ ). Once a sufficient number of fractures has been activated, subsequent extension favours continued growth of the activated fractures, rather than the activation of new ones. The fractures unite to connect the magma to the surface, and so it is this stage that is associated with the final acceleration in seismicity before eruption. The seismic event rate now depends on the rate of reactivation of the same fractures, a condition that yields a hyperbolic increase with time (following a Boltzmann distribution for the probability of reactivation), equivalent to equation (2) with $\alpha=2$ [Kilburn, 2003].

[7] During the hyperbolic acceleration, growth steps for the largest fractures can be followed using the temporary peaks in event rate $d N_{p} / d t$, for which the inverse-rate trend is given by (Figure 1) [Kilburn, 2003]:

$$
\left(d N_{p} / d t\right)^{-1}=\left(d N_{p} / d t\right)_{0}^{-1}-\gamma^{*}\left(t-t_{0}\right)
$$


a
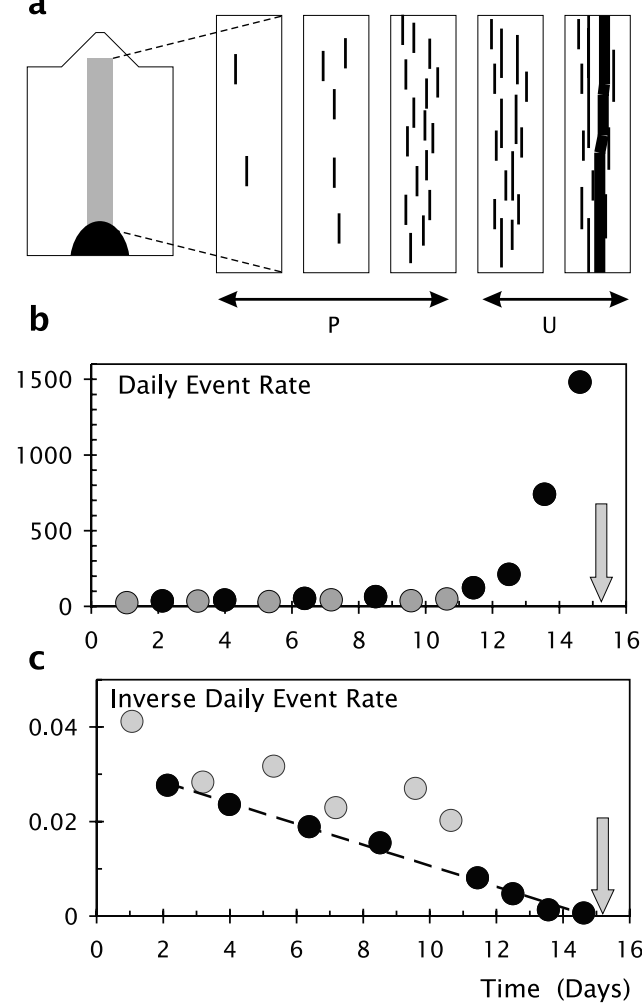

Figure 1. (a) Precursory seismicity develops within a restricted volume (grey) between the magma reservoir (black) and the surface. During a Preparation Stage $(P)$, seismicity is controlled by an increasing number of activated fractures. These fractures eventually unite to form a connected fracture across the seismic volume (Unification Stage, $U$ ). (b) Unification is characterised by a hyperbolic increase in peak event rate (black circles), corresponding in c to a linear decrease in the inverse-rate minima (black circles and broken line; equation (2)). The event rate data [Kilburn and Voight, 1998] are for precursors to the 1995 eruption of Soufriere Hills volcano, Montserrat, measured from 00.00 on 01 November; lava emerged on 15 November (arrow). Note how 5 datapoints (until Day 11) may have been required to identify with confidence a linear trend in the inverse-rate minima.

where $\left(d N_{p} / d t\right)_{0}$ is the peak event rate at the start of the final acceleration at time $t_{0}$, and the gradient $\gamma^{*}$ is

$$
\gamma^{*}=\left[S_{f}^{2} / Y f(\nu)\right] V /(n R T)=\left[S_{f}^{2} / Y f(\nu)\right] W_{m} /(\rho R T)
$$

where $S_{f}$ is the differential stress (assumed constant) applied across the volume $V$, which contains $n$ moles of rock (with mean density $\rho$ and mean molecular weight $\left.W_{m}\right), R$ is the Boltzmann Constant $\left(8.314 \mathrm{~J} \mathrm{~mole}^{-1} \mathrm{~K}^{-1}\right), T$ is rock temperature in Kelvin, and $f(\nu)$ is a function of Poisson's ratio, $\nu . \gamma^{*}$ is derived from the energy changes during crack growth and assumes elastic deformation around fracture tips under plane stress or plane strain conditions; for plane stress, $f(\nu)=1$, and for plane strain, $f(\nu)=\left(1-\nu^{2}\right)^{-1}$ [Lawn, 1993]. For fracturing of crust between a magma reservoir and the surface, the plain-strain approximation is more appropriate [Jaeger, 1969]; however, given that $\nu \approx$ 0.3 for most rock, $f(\nu)$ can normally be approximated to 1 .

\section{Damage Mechanics}

[8] Taking $S_{f}$ as the maximum stress for elastic crustal behaviour, representative values of rock properties under subvolcanic conditions yield $\gamma^{*}=(4.5 \pm 3.2) \times 10^{-3}$ for shear failure at the elastic limit (for which $S_{f}^{2} / Y \sim 10^{5} \mathrm{~J} \mathrm{~m}^{-3}$ ). As discussed by Kilburn [2003], this range is consistent with accelerations in seismic event rate before the eruptions of Pinatubo, Philippines, in $1991\left(\gamma^{*}=6.4 \times 10^{-3}\right)$, and of Soufriere Hills, Montserrat, in $1995\left(\gamma^{*}=2.4 \times 10^{-3}\right)$, two subduction-zone volcanoes that produced andesiticdacitic magma after centuries of repose [Newhall and Punongbayan, 1996; Druitt and Kokelaar, 2002]. However, the interpretation of $S_{f}$ as a shear strength implies crustal failure at overpressures $\sim 100 \mathrm{MPa}$ [Lockner, 1995; Rocchi et al., 2004], in conflict with the conventional views that (1) the walls of magma reservoirs fracture in tension at overpressures on the order of the crust's tensile strength ( $10 \mathrm{MPa})$ [Blake, 1984], and (2) that magma can open and ascend through new fractures at overpressures of about 10-40 MPa [Rubin, 1995; Jellinek and DePaolo, 2003]. The implication is that, even for a compressional tectonic regime, a new fracture system can develop in tension, owing to the stress on the crust from pressure in the magma reservoir.

[9] The apparent conflict in controlling strength can be resolved by introducing a simple damage-mechanics criterion for reinterpreting the strain energy at which a fracture cuts across the entire volume $V_{s}$. Major fractures propagate by the growth and coalescence of smaller fractures around their tips [Atkinson, 1984]. Growth of a major fracture is thus resisted not by the elastic properties of homogeneous rock between extending faults, but by the effective elastic properties of fractured crust, which becomes weaker as the degree of small-scale fracturing increases (Figure 2). Such weakening can be described [Lyakhovsky et al., 1997; Scherbakov and Turcotte, 2004] by substituting Young's Modulus with an effective modulus $Y^{\prime}$, given by:

$$
Y^{\prime}=Y(1-a)
$$

where $Y$ remains the Young's Modulus for unbroken rock, and $a$ measures the degree of damage by small-scale cracking. The effective modulus thus decreases as cracking continues. In theory, $a$ lies between 0 (unbroken crust) and 1 (complete bulk failure). In practice, experimental data [Rocchi et al., 2004] suggest that bulk failure normally occurs when $a=a_{f} \approx 0.9$ (Figure 2).

[10] The original derivation of $\gamma^{*}$ for compressional failure used $S_{f}^{2} / Y f(\nu) \sim 10^{5} \mathrm{~J} \mathrm{~m}^{-3}$ (nominally 1 to $3 \times$ $10^{5} \mathrm{~J} \mathrm{~m}^{-3}$ ). If $Y$ is replaced $Y^{\prime}$ (equation (4)), the condition for tensile failure to yield the same values for $\gamma^{*}$ requires that $S_{f}^{2} / Y\left(1-a_{f}\right) f(\nu) \sim 10^{5} \mathrm{~J} \mathrm{~m}^{-3}$. Applying this constraint, and setting $Y$ between 20 and $50 \mathrm{GPa}$ for unaltered crust [Jaeger, 1969; Rocchi et al., 2004], $S_{f}$ takes values of 14 to $23 \mathrm{MPa}$, indicating magmatic overpressures that are indeed consistent with local tensile failure and magma injection (Figure 2). Thus, by introducing the damage-mechanics criterion, conditions for local tensile failure can regain the 
a
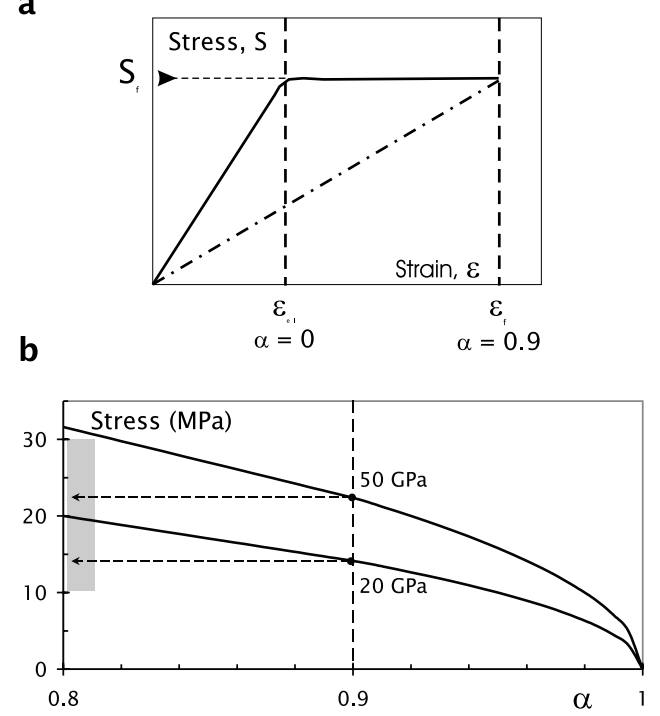

Figure 2. (a) For applied stresses less than $S_{f}$, intact crust deforms elastically to a maximum strain $\varepsilon_{e l}$, such that $S_{f}=$ $Y \varepsilon_{e l}$. At $S_{f}$, cracks begin to grow as a damage zone until they are sufficiently numerous to cause failure (at strain $\varepsilon_{f}$ ) across the volume under stress. The effect of the damage zone is modelled by the parameter $a$ (equation (4)). In experiments, $a$ appears to increase from 0 to 0.9 , at which point $\varepsilon_{f} / \varepsilon_{e l} \approx$ 10 (not to scale). (b) Assuming $S_{f} \varepsilon_{\mathrm{f}}=10^{5} \mathrm{~J} \mathrm{~m}^{-3}$, values of Young's Modulus between 20 and $50 \mathrm{GPa}$ yield failure stresses $\left(a_{f}=0.9\right)$ of 14 to $23 \mathrm{MPa}$, within the nominal range for crustal tensile strength (shaded).

numerical results from the bulk shear model if $\gamma^{*}$ is reinterpreted as

$$
\gamma^{*}=\left[S_{f}^{2} / Y\left(1-a_{f}\right) f(\nu)\right]\left[W_{m} / \rho R T\right]
$$

where $S_{f}$ is now the critical stress in tension.

\section{Critical Strain for Bulk Failure}

[11] Equations (3) and (5) imply that $\gamma^{*}$ is the ratio, per unit volume, of the energy for tensile failure $\left[S_{f}^{2} / Y\left(1-a_{f}\right)\right.$ $f(\nu)]$ to a rock's internal energy $(n R T / V)$. This interpretation, however, does not explain why $\gamma^{*}$ should show a restricted range of values. From classical thermodynamics [Young, 1992], atoms in solids have an average potential energy, associated with elastic deformation, of $(1 / 2)(n R T / V)$ for each of their three components of motion. Because the strain at failure, $\varepsilon_{f}$, can be defined as the ratio, per unit volume, of [Strain Energy for Fracture] to [Initial Potential Energy], it follows that $\varepsilon_{f}=(2 / b) V\left[S_{f}^{2} / Y\left(1-a_{f}\right)\right] /(n R T)=$ $(2 / b) \gamma^{*}$, where $b$ denotes the number of dimensions along which deformation is concentrated. For the assumed planestrain condition, $b=2$ and so $\gamma^{*}=\varepsilon_{f}$. The ratio $\gamma^{*}$ is thus interpreted as the critical mean strain at which a fracture extends across the volume under stress. Given that common crustal materials beneath volcanoes are likely to share a similar and restricted range of fracture mechanical properties, the critical strain at fracture and, hence, $\gamma^{*}$ are also expected to lie within a restricted range. The revised interpretation of $\gamma^{*}$ also yields critical strains at tensile failure consistent with equation (4). Thus, from equation (4), $\varepsilon_{f} \sim S_{f} / Y\left(1-a_{f}\right)$, yielding a critical strain of $(6 \pm 2) \times 10^{-3}$, compared with the range $(4.5 \pm 3.2) \times 10^{-3}$ from the criterion $\gamma^{*}=\varepsilon_{f}$.

\section{Reliable Short-Term Warning Times}

[12] Further support for a restricted range of fracturing conditions comes from equation (2), which can be normalised to:

$$
\Psi=\left(t_{e}-t\right) / \Delta \tau
$$

where the normalised inverse rate $\Psi=\left[\left(d N_{p} / d t\right)^{-1} /\left(d N_{p} /\right.\right.$ $\left.d t)_{0}^{-1}\right]$ and $\Delta \tau=\left[\gamma^{*}\left(d N_{p} / d t\right)_{0}\right]^{-1}$ is the timescale over which the final, hyperbolic acceleration in seismic event rate develops.

[13] The term $\left(d N_{p} / d t\right)_{0}$ measures the event rate at which the mean strain reaches $\gamma^{*}$ and the detected seismicity becomes dominated by the unification of reactivated fractures. For the 1991 Pinatubo and 1995 Soufriere Hills eruptions [Kilburn, 2003], empirical estimates of $\left(d N_{p} / d t\right)_{0}$ are, respectively, 1 to 3 events per 4 hours and 20 to 35 events per day (using the units as originally reported by Harlow et al. [1996] and Kilburn and Voight [1998]). Combined with the corresponding values for $\gamma^{*}$, the two data sets can be made to follow identical normalised trends for $\Delta \tau$ between 12 and $20 \mathrm{~d}$ (Figure 3 ). Similar conditions are thus indicated for the final evolution of the magmatic systems feeding Pinatubo and Soufriere Hills.

[14] The timescale $\Delta \tau$ represents the theoretical maximum time available to warn of an eruption using accelerations in seismic event rate. In practice, more than half this time might be required to confirm the onset of a hyperbolic (as opposed to an exponential) increase in event rate. At least four or five datapoints are required to identify with confidence a hyperbolic acceleration in peak seismicity (or linear decrease in the inverse-rate minima; Figure 1). At best, therefore, reliable short-term warning times are likely to be on the order of days for andesitic-dacitic volcanoes that reawaken in subduction-zone settings after a century or more of repose. Such eruption conditions favour long warning times, since compressional tectonics and an ex-

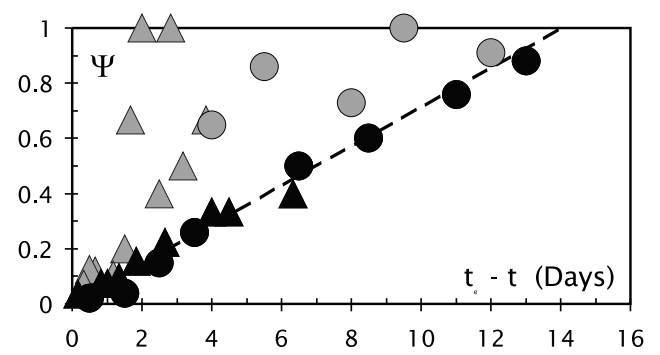

Figure 3. Normalised inverse-rate trends for Pinatubo (triangles) and Soufriere Hills (circles), following equation (6). This example takes initial event rates of $2(4 \mathrm{~h})^{-1}$ for Pinatubo and $32 \mathrm{~d}^{-1}$ for Soufriere Hills (within the ranges in main text), for which the normalised inverse-rate minima (in black) fall on the same trend and correspond to a unification timescale, $\Delta \tau$, of 14 days (within the $16 \pm 4 \mathrm{~d}$ of the main text). 
tended preceding repose favour the healing of earlier fractures and thus an increased crustal resistance to renewed magma ascent. Accordingly, shorter warning times are to be expected at volcanoes that (1) are found in extensional tectonic regimes and (2) have short repose intervals (and so times too short for fractures to heal effectively), because both factors would favour magma reaching the surface after a smaller degree of additional crustal fracturing. Indeed, recent studies at the frequently erupting basaltic volcanoes Kilauea [Chastin and Main, 2003] and Piton de La Fournaise [Collombet et al., 2003] suggest that short-term forecasts may be reliable only about 24 hours or less ahead of time.

[15] The present model describes the growth of a fracture system and, for use in forecasting eruptions, it is assumed that this fracture system connects a magma body to the surface. In principle, however, a similar fracture system might develop that (1) does not intersect with either the magma body or the surface, or (2) allows magma to move through the crust without reaching the surface. In both cases, a hyperbolic increase in seismic event rate might be recorded without culminating in eruption, leading to a false alarm. Optimistically, it might eventually prove possible to distinguish eruptive from non-eruptive trends by combining the seismic data with additional precursory signals, such as changes in ground deformation. Until then, statistical analyses must be employed to assess the probability that a given hyperbolic increase in seismic event rate may in fact lead to an eruption.

\section{Conclusions}

[16] At subduction-zone volcanoes reawakening after centuries of repose, accelerations in seismic event rate shortly before eruption are consistent with the linkage of crustal fractures extending under magmatic overpressure. Failure occurs over some two to three weeks at the critical strain for bulk failure. However, using seismic precursors alone, only a few days at best can be expected for reliable short-term warnings of eruptions. This limit severely constrains plans for mitigating volcanic hazard, especially when the evacuation of vulnerable populations requires a longer time interval.

[17] Improved mitigation will follow if reliable warning intervals can be extended through additional geophysical or geochemical precursors, or by the extension of the current model to preceding conditions of fracture growth. Otherwise, evacuations may have to be implemented at an earlier stage of unrest, taking account of the greater probability of a false alarm.

[18] Acknowledgments. This paper benefited from lively discussions with Andrew Bell and Philip Meredith (both at UCL) and from comments by Valerio Acocella and an anonymous reviewer. The research was funded by the European Commission (DG Research, Environment and Climate Programme) for Project Volcalert (contract EVG-CT-2000-00047) and by the Gruppo Nazionale per la Vulcanologia, Italy.

\section{References}

Atkinson, B. K. (1984), Subcritical crack growth in geological materials, J. Geophys. Res., 89, 4077-4114.

Blake, S. (1984), Volatile oversaturation during the evolution of silicic magma chambers as an eruption trigger, J. Geophys. Res., 89, 82378244

Chastin, S. F. M., and I. G. Main (2003), Statistical analysis of daily seismic event rate as a precursor to volcanic eruptions, Geophys. Res. Lett., 30(13), 1671, doi:10.1029/2003GL016900.

Collombet, M., J. Grasso, and V. Ferrazzini (2003), Seismicity rate before eruptions on Piton de la Fournaise volcano: Implications for eruption dynamics, Geophys. Res. Lett., 30(21), 2099, doi:10.1029/ 2003 GL017494.

Druitt, T. H., and B. P. Kokelaar (Eds.) (2002), The Eruption of Soufriere Hills Volcano, Montserrat From 1995 to 1999, Geol. Soc. Mem., 21.

Endo, E. T., S. D. Malone, L. L. Noson, and C. S. Weaver (1981), Locations, magnitudes and statistics of the March 20-May 18 earthquake sequence, U.S. Geol. Surv. Prof. Pap., 1250, 93-107.

Harlow, D. H., J. A. Power, E. P. Laguera, G. Ambubuyong, R. A. White, and R. P. Hoblitt (1996), Precursory seismicity and forecasting of the June 15, 1991 eruption of Mount Pinatubo, Philippines, in Fire and Mud: Eruptions and Lahars of Mount Pinatubo, Philippines, edited by C. G. Newhall and R. S. Punongbayan, pp. 285-305, Univ. of Wash. Press, Seattle.

Hill, D. P., F. Pollitz, and C. Newhall (2002), Earthquake-volcano interactions, Phys. Today, 55(11), 41-47.

Jaeger, J. C. (1969), Elasticity, Fracture and Flow, 3rd ed., CRC Press, Boca Raton, Fla.

Jellinek, M. A., and D. J. DePaolo (2003), A model for the origin of large silicic magma chambers, precursors of caldera-forming eruptions, Bull. Volcanol., 65, 363-381.

Kilburn, C. R. J., and B. Voight (1998), Slow rock fracture as eruption precursor at Soufriere Hills volcano, Montserrat, Geophys. Res. Lett., 25, $3665-3668$

Kilburn, C. R. J. (2003), Multiscale fracturing as a key to forecasting volcanic eruptions, J. Volcanol. Geotherm. Res., 125, 271-289.

Lawn, B. (1993), Fracture of Brittle Solids, 2nd ed., Cambridge Univ. Press, New York

Linde, A. T., K. Ágústsson, I. S. Sacks, and R. Stefánsson (1993), Mechanism of the 1991 eruption of Hekla from continuous borehole strain monitoring, Nature, 365, 737-740.

Lockner, D. A. (1995), Rock failure, in Rock Physics and Phase Relations, $A G U$ Ref. Shelf, vol. 3, edited by T. J. Ahrens, pp. 127-147, AGU, Washington, D. C.

Lyakhovsky, V., Y. Ben-Zion, and A. Agnon (1997), Distributed damage, faulting, and friction, J. Geophys. Res., 102, 27,635-27,649.

McGuire, W. J., and C. R. J. Kilburn (1997), Forecasting volcanic events: Some contemporary issues, Geol. Rundsch., 86, 439-445.

Newhall, C. G., , and R. S. Punongbayan (Eds.) (1996), Fire and Mud: Eruptions and Lahars of Mount Pinatubo, Philippines, Univ. of Wash. Press, Seattle.

Rocchi, V., P. Sammonds, and C. R. J. Kilburn (2004), Fracturing of Etnean and Vesuvian rocks at high temperatures and low pressures, J. Volcanol. Geotherm. Res., 132, 137-157.

Rubin, A. M. (1995), Getting granite dikes out of the source region, J. Geophys. Res., 100, 5911-5929.

Scarpa, R., and R. I. Tilling (Eds.) (1996), Monitoring and Mitigation of Volcanic Hazards, Springer, New York.

Scherbakov, R., and D. L. Turcotte (2004), A damage mechanics model for aftershocks, Pure Appl. Geophys., 161, 2379-2391.

Simkin, T., and L. Siebert (1994), Volcanoes of the World, 2nd ed., Geosci. Press, Tucson, Ariz.

Voight, B. (1988), A method for prediction of volcanic eruptions, Nature, $332,125-130$.

Voight, B. (1989), A relation to describe rate-dependent material failure, Science, 243, 200-203.

Young, H. D. (1992), Physics, Addison-Wesley, Boston, Mass.

C. R. J. Kilburn and P. R. Sammonds, Department of Earth Sciences, University College London, Gower Street, London WC1E 6BT, UK. (c.kilburn@ucl.ac.uk) 